\title{
An immunogenetic heterogeneity in multiple sclerosis
}

\author{
Jan Hillert, Marit Grönning, Harald Nyland, Hans Link, Olle Olerup
}

\begin{abstract}
Two clinical forms of multiple sclerosis (MS), primarily chronic progressive MS (PCP MS) and relapsing/remitting MS (R/R MS) have been shown to differ in several respects. The results of genomic HLA class II typing with restriction fragment length polymorphism analysis of 62 MS patients from Western Norway, 42 with R/R MS and 20 PCP MS, are reported on here. As in previous studies of Swedish patients, the haplotype DRw17(3), DQw2 was found to be five times more common in R/R MS than in PCP MS. This finding supports the hypothesis that $R / R$ and $P C P$ MS are immunogenetically separate entities. In contrast with a previous investigation of Norwegian MS patients, no association of $M S$ with glutamine at position 34 of the HLA-DQ $\alpha$ chain or with defined sequences of the $H L A-D Q B 1$ gene was found.
\end{abstract}

(F Neurol Neurosurg Psychiatry 1992;55:887-890)

In recent years, the use of genomic HLA class II typing techniques, offering improved accuracy as well as resolution, has resulted in a clearer picture of HLA class II associations in a number of diseases such as insulin dependent diabetes mellitus, ${ }^{1}$ rheumatoid arthritis ${ }^{2}$ and IgA deficiency. ${ }^{3}$ For multiple sclerosis (MS), the long established association in white patients with HLA-DR2,Dw2 has been specified to the HLA-DRw15,DQw6,Dw2 haplotype. ${ }^{45}$ In addition, a number of results have been published that have yet to be confirmed. For instance, MS has been reported to be more closely associated with the $H L A-D Q$ than with the $-D R$ subregion $^{4}$ as well as with defined sequences of the $D Q B 1^{6}$ and $D Q A 1^{7}$ genes. Furthermore, a report has suggested association of MS with HLA-DP alleles. ${ }^{8}$

We previously reported that among Swedish MS patients, two clinical subtypes, relapsing or remitting MS (R/R MS) and primarily chronic progressive MS (PCP MS), in addition to the association with the DRw15,DQw6,Dw2 haplotype, possess different associations with DR-DQ haplotypes. ${ }^{5}$ The DRw17,DQw2, D2 haplotype was found to be significantly increased in R/R MS, whereas DRw4, DQw8 was found to be more common in PCP MS. Furthermore, we have recently confirmed our finding of an increased frequency of the DRw17,DQw2,D2 haplotype in a new group of Swedish patients with R/R MS. ${ }^{9}$ In other respects, R/R MS and PCP MS have also been found to differ in epidemiology ${ }^{10}$ and appearance on MRI. ${ }^{112}$ Thus, different observations indicate that $R / R$ and PCP MS might be recognised as separate disease entities.

The aim of the present study was to investigate whether differences in the distribution of HLA-DR-DQ haplotypes between R/R MS and PCP MS could be observed in an independent Norwegian group of MS patients.

\section{Patients and methods}

\section{Patients}

Sixty two unrelated patients with clinically definite MS and 98 controls, matched for sex and area of residence, were studied. Both groups had participated in a recent population based, case control study at the Department of Neurology, University of Bergen (Grönning $e t$ $a l$, submitted). Forty two patients were classified as having R/R MS, since they had only experienced a relapsing/remitting course of the disease. Twenty patients, classified as having PCP MS, had already from onset a course of disease characterised by steady progression without remissions. Patients who after a relapsing/remitting onset eventually had entered a secondary chronic progressive phase were not included in this study. Mean age of onset was 28.8 years in the R/R MS group and 41.5 years in the PCP MS group. Twenty-six out of 42 R/R MS patients (62\%) and 13 of 20 PCP MS patients $(65 \%)$ were women.

\section{Methods}

Southern blot analysis: Extraction of DNA from peripheral blood leucocytes, restriction enzyme digestions ( $T a q \mathrm{I}$ and $M s p \mathrm{I}$ ), agarose gel electrophoresis, capillary blotting to nylon membranes, labelling of probes, ${ }^{5}$ hybridisation, stringency washes, and autoradiography were performed using standard techniques.

TaqI $H L A-D R$ and $-D Q$ restriction fragment length polymorphism (RFLP) analysis: Genomic DR typing and DQ typing was performed by hybridising TaqI cleaved DNA with $D R B$, $D Q A$ and $D Q B$ cDNA probes. Allelic restriction fragments were designated by the associated serologically defined $D R$ and $D Q$ specificities according to previous reports. ${ }^{1{ }^{14}}$ $M s p$ I $H L A-D P$ RFLP analysis: DP typing was performed by hybridising MspI cleaved DNA with $D P A$ and $D P B$ cDNA probes. Allelic fragment patterns were designated by the associated cellularly defined DP specificities according to Hyldig-Nielsen et al. ${ }^{15} 16$ 
PCR-SSO analysis of DR4 subtypes: In vitro amplification of genomic DNA by polymerase chain reaction (PCR), followed by dot-blot and hybridisation with five sequence specific oligonucleotide (SSO) probes was performed according to Lanchbury ${ }^{17}$ with slight modifications. ${ }^{9}$

DR7/DR9 separation by PCR amplification with sequence specific primers: TaqI HLA-DRDQ RFLP analysis cannot distinguish between the haplotypes DR7, DQw9 and DR9, DQw9. This was achieved by PCR amplification of genomic DNA with oligonucleotide primer pairs specific for the $D R B 1$ second exon gene sequences for DR7 and DR9 respectively. ${ }^{18}$ Amplification was detected by ethidium bromide stained agarose gel electrophoresis.

\section{Statistical analysis}

Data were analysed by the Chi-square test or by Fishers test of exact probability in case of small numbers. Probability $(p)$ values were corrected with a factor of 60 for the number of DR-DQ haplotypes $(n=24)$ and DP alleles $(n=6)$ and the two groups of patients. When looking for confirmation of a previous observation no correction of the $p$ value was used. The strength of associations are given by the relative risk (RR).

\section{Results}

Associations with HLA-DR-DQ haplotypes in MS: The distribution of the DR-DQ haplotypes among MS patients and controls is given in table 1. The DRw15, DQw6 haplotype was significantly increased among the whole group of MS patients $\left(p<10^{-4}\right)$, and equally associated with R/R MS $\left(p<10^{-3}\right)$ and PCP MS $\left(p<10^{-3}\right)$. All DRw15, DQw6 positive MS patients carried the RFLP patterns corresponding to the cellularly defined specificity Dw2.

We have previously shown that the haplotype DRw17,DQw2 is more common in R/R MS compared with both controls and PCP MS. ${ }^{59}$ It was five times more frequent among $R / R$ MS patients than PCP MS patients although this difference did not reach statistical significance

Table 1 Distribution (\%) of HLA-DR-DQ phenotypes in $M S$ patients and control subjects

\begin{tabular}{lcccc}
\hline $\begin{array}{l}H L A-D R-D Q \\
\text { haplotype }\end{array}$ & $\begin{array}{c}P C P M S \\
(n=20)\end{array}$ & $\begin{array}{c}R / R M S \\
(n=42)\end{array}$ & $\begin{array}{c}\text { All MS } \\
(n=62)\end{array}$ & $\begin{array}{c}\text { Controls } \\
(n=98)\end{array}$ \\
\hline DR1, DQw5 & 20 & 12 & 15 & 19 \\
DRw15 (2), DQw6 & $75^{\star}$ & $64^{\star}$ & $68^{\star \star}$ & 32 \\
DRw16 (2), DQw5 & 5 & 0 & 2 & 1 \\
DRw17 (3), DQw2 & 5 & 24 & 18 & 25 \\
DR4, DQw7 & 5 & 5 & 5 & 9 \\
DR4, DQw8 & 25 & 29 & 27 & 25 \\
DRw11 (5), DQw7 & 5 & 0 & 2 & 12 \\
DRw12 (5), DQw7 & 5 & 5 & 5 & 1 \\
DRw13 (w6), DQw6 & 15 & 14 & 15 & 23 \\
DRw13 (w6), DQw7 & 0 & 0 & 0 & 2 \\
DRw14 (w6), DQw5 & 0 & 5 & 3 & 6 \\
DR7, DQw2 & 10 & 12 & 11 & 7 \\
DR7, DQw9 & 5 & 10 & 8 & 14 \\
DRw8, DQw4 & 15 & 12 & 13 & 7 \\
DRw8, DQw7 & 0 & 0 & 0 & 1 \\
DR9, DQw9 & 0 & 0 & 0 & 1 \\
DRw10, Dqw5 & 5 & 0 & 2 & 1 \\
\end{tabular}

${ }^{*} p<10^{3}$

$\star \star p<10$

MS = multiple sclerosis

$\mathrm{PCP}=$ primarily chronic progressive

$R / R=$ relapsing or remitting. $(p<0 \cdot 10, \mathrm{RR} 5.9)$. The frequency of the DRw17,DQw2 haplotype did not differ between the $R / R$ MS group and controls whereas the frequency was markedly lower among PCP MS patients than controls $(p<0.09)$. In contrast to our previous report, ${ }^{5}$ no difference was observed in the frequency of the DR4, DQw8 haplotype between PCP MS and R/R MS.

The allele DQw7, previously reported to be decreased in groups of MS patients ${ }^{519}$ was less frequent in MS patients compared with controls $(p<0.03$, RR 0.52). When DRw15 positive patients and controls were excluded from the analysis, however, a statistical significance was no longer reached, although the relative risk was left unchanged (RR 0.35). Cellularly defined subtypes of DR4: The frequencies of Dw4, Dw10, Dw14, and Dw15 as determined by PCR-SSO analysis is shown in table 2. There was no significant difference between the various groups.

HLA-DP alleles: No significant differences were found in the distribution of HLA-DP alleles (see table 3 ).

HLA-DQB1 and $D Q A 1$ sequences: Table 4 shows the frequencies of carriers of the long

Table 2 Phenotypic distribution (\%) of Dw specificities among DR4-positive haplotypes in MS patients and controls

\begin{tabular}{llccc}
\hline $\begin{array}{l}\text { Dw } \\
\text { specificity }\end{array}$ & $\begin{array}{l}P C P M S \\
(n=6)\end{array}$ & $\begin{array}{c}R / R M S \\
(n=14)\end{array}$ & $\begin{array}{c}\text { All MS } \\
(n=22)\end{array}$ & $\begin{array}{l}\text { Controls } \\
(n=31)\end{array}$ \\
\hline Dw4 & 100 & 64 & 75 & 58 \\
Dw10 & 0 & 0 & 0 & 0 \\
Dw13 & 0 & 7 & 5 & 6 \\
Dw14 & 0 & 36 & 25 & 39 \\
Dw15 & 0 & 0 & 0 & 3 \\
\hline
\end{tabular}

Table 3 Frequencies (\%) of HLA-DP phenotypes in MS patients and controls

\begin{tabular}{lcclc}
\hline $\begin{array}{l}\text { DP } \\
\text { allele }\end{array}$ & $\begin{array}{c}P C P M S \\
(n=20)\end{array}$ & $\begin{array}{l}R / R M S \\
(n=42)\end{array}$ & $\begin{array}{l}\text { All MS } \\
(n=62)\end{array}$ & $\begin{array}{l}\text { Controls } \\
(n=63)\end{array}$ \\
\hline DPw1 & 0 & 14 & 10 & 14 \\
DPw2 & 20 & 21 & $21^{\star \star}$ & 8 \\
DPw3/DPw6* & 35 & 36 & 35 & 49 \\
DPw4 & 95 & 81 & 85 & 86 \\
DPw5 & 10 & 7 & 8 & 10 \\
CDP HEI & 0 & 0 & 0 & 3 \\
\hline
\end{tabular}

${ }^{\star} \mathrm{DPw} 3$ and DPw6 cannot be separated by MspI RFLP ${ }_{\star \star \star}^{\text {typing. }}{ }^{19}{ }_{\text {uncorr }}<0.05 ; P_{\text {corr }}$ n.s.

Table 4 Frequencies (\%) of carriers of a $D Q B 1$ sequence corresponding to amino acid residues 24-29, shared by the $D Q B 1$ alleles $D Q B 1{ }^{\star} 0602,{ }^{\star} 0603,{ }^{\star} 0604,{ }^{\star} 0302$ and ${ }^{\star} 0303$, and of a glutamine at position 34 of the DQa chain, respectively

\begin{tabular}{lll}
\hline & $\begin{array}{l}\text { Carriers of } \\
\text { shared } D Q B 1 \\
\text { sequence }\end{array}$ & $\begin{array}{l}\text { Carriers of glutamine } \\
\text { at position } 34 \\
\text { of } D Q a \text { chain }\end{array}$ \\
\hline A. All individuals & \\
PCP MS $(\mathrm{n}=20)$ & 80 & 85 \\
R/R MS $(\mathrm{n}=42)$ & 88 & 88 \\
All MS $(\mathrm{n}=62)$ & 85 & 87 \\
Controls $(\mathrm{n}=98)$ & 77 & 81 \\
B. DR2-negative individuals only & \\
PCP MS $(\mathrm{n}=5)$ & 20 & 40 \\
R/R MS $(\mathrm{n}=15)$ & 67 & 67 \\
All MS $(\mathrm{n}=20)$ & 55 & 60 \\
Controls $(\mathrm{n}=66)$ & 65 & 71
\end{tabular}


stretches of $D Q B 1$ gene second exon sequences shared by the haplotypes DRw 15,DQw6, DR4,DQw8, DR7,DQw9, DR9,DQw9 and DRw13(6),DQw6 among MS patients and controls and of a glutamine at position 34 of the $D Q \alpha$ chain. These data were inferred from the $D R B-D Q A-D Q B$ haplotypes assigned by TaqI RFLP in accordance with the previously shown very high correlation (97-99\%) between PCR-SSO typing results and TaqI RFLP data of the $H L A-D Q A 1$ and $H L A-D Q B 1$ genes. The minor differences observed disappeared when DRw15-positive individuals were excluded.

\section{Discussion}

Although attempts to subdivide MS clinically are hampered by the tendency of patients to change from one clinical form to another during follow up, ${ }^{20}$ chronic progressive course of the disease already from onset is a readily distinguishable clinical pattern that in our experience persists with few, if any, exceptions. In different reports $10-40 \%$ of MS patients are classified into this group, ${ }^{21}{ }^{22}$ here referred to as primarily chronic progressive (PCP) MS to distinguish them from secondary progression that follows an initially relapsing or remitting course of MS.

PCP MS has been shown to differ from $R / R$ MS in several respects. Age at onset tends to be higher, approximately at 40 in PCP MS compared with approximately 30 years in $R / R$ MS. ${ }^{51023}$ Predominance among women is sometimes ${ }^{24-26}$ but not invariably ${ }^{1027}$ less obvious. Furthermore, spinal symptoms are common $^{1027}$ and acute optic neuritis is rare in this group. ${ }^{25}$ Epidemiologically, in a study from Western Norway, PCP MS showed a constant incidence over a 30 year period, whereas $R / R$ MS showed a clear increase in incidence. ${ }^{10}$ Recently, MRI has been reported to show differences in type, number, and occurrence rate of lesions between patients with primary and secondary progression. ${ }^{112}$

Table 5 shows that the distribution of the DRw17, DQw2 haplotype was strikingly similar in our three different studies. Although the difference in the present study between PCP and $R / R$ MS did not reach statistical significance, it was of the same order, the haplotype being five times more common in $\mathrm{R} / \mathrm{R}$ than in PCP $\mathrm{MS}$ and the relative risks

Table 5 Similar phenotypic frequencies (\%) of the haplotype DRw17 (3), DQw2 in PCP MS and R/R MS patients and controls in our three separate studies

\begin{tabular}{|c|c|c|c|}
\hline & $P C P M S$ & $R / R M S$ & Controls \\
\hline First Swedish study ${ }^{5}$ & $\begin{array}{l}4^{\star} \\
(n=26)\end{array}$ & $\begin{array}{l}32^{\star \star \star} \\
(n=74)\end{array}$ & $\begin{array}{l}15 \\
(n=100\end{array}$ \\
\hline Second Swedish study ${ }^{9}$ & $\begin{array}{l}10 \\
(n=10)\end{array}$ & $\begin{array}{l}22^{\star \star \star \star} \\
(n=69)\end{array}$ & $\begin{array}{l}19 \\
(n=150\end{array}$ \\
\hline $\begin{array}{l}\text { Norwegian study } \\
\text { (present study) }\end{array}$ & $\begin{array}{c}5^{\star \star} \\
(n=20)\end{array}$ & $\begin{array}{l}24 \\
(n=42)\end{array}$ & $\begin{array}{l}25 \\
(n=98)\end{array}$ \\
\hline
\end{tabular}

${ }^{\star} \mathrm{p}<0.005$

${ }_{\star \star \star} p<0.005$

$\star x_{\star \star \star} \mathrm{p}<0.0005$

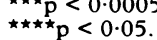

accordingly similar, 5.9 and 6.4 , respectively. The lack of significance is likely to be a result of the smaller number of patients in the present study.

In contrast to our findings, a recent Norwegian report did not show any differences in HLA DR-DQ haplotype distribution between R/R MS and a small group of eleven PCP MS patients, ${ }^{7}$ while both Madigand $e t$ al ${ }^{28}$ and van Lambalgen et $a P^{4}$ reported an increase of the DR3 allele in PCP MS although this was not statistically significant compared with R/R MS in the former group. These divergent results could reflect either ethnic or methodological differences, where assignment of patients to the PCP MS category is the most obvious point. The uniform way in which patients have been categorised in the present and our previous studies, may be the explanation for our consistent findings. For instance, the inclusion of patients with very malignant MS characterised by severe relapses occurring with short intervals, leading to rapidly progressing disease, into the PCP group, could change the outcome of the results. Such patients, when relapses are discernible close in time, have been classified as R/R MS in our studies, and furthermore often been noted to be DR3positive. All patients classified as PCP in our studies have experienced a gradual onset and progression of symptoms and, less frequently and later in the course, periods of general deterioration resembling relapses.

Considerable efforts have been made recently to delineate the HLA class II association in MS to a more precise location within the HLA-DR-DQ region. In this populationbased study from Western Norway, as in a large study of Swedish patients, ${ }^{9}$ we could not confirm the reported association with two concensus sequences of the $D Q A 1$ and $D Q B 1$ genes, ${ }^{67}$ respectively. Similar negative results concerning $D Q B 1$ have been reported in another recent paper. ${ }^{29}$ Analysis of published sequences $^{30}$ furthermore disclose such differences between the $D R B 1, D Q A 1$ and $D Q B 1$ alleles of the two haplotypes DRw15, DQw6, Dw2 and DRw17, DQw2 associated with MS, that a common denominator sequence cannot be identified. We conclude, therefore, that it is still not possible to settle the issue whether MS is more closely associated with either HLA-DR or HLA-DQ genes.

It is tempting to speculate how the present results could reflect a dividing line between two different disease entities. The HLA class II genes act as immune response genes both by the ability of the class II molecules to bind and present antigens to the $T$ helper cell and by shaping the repertoire of $T$ cell receptor specificities that occurs during thymic maturation of $T$ cells. Assuming that autoimmune mechanisms are involved in the aetiology or pathogenesis of MS, it is feasible that the HLA phenotype influences either the immune response to a triggering exogenous factor such as an infectious agent or the likelihood for potentially autoreactive $T$ cell clones to exist and to become activated. Consequently, autoreactivity towards an antigen or antigen epi- 
tope with a certain distribution within the central nervous system, secondarily influenced by sex hormones and state of the immune system depending on the age of the individual could influence the outcome in terms of symptoms as well as sex and age distribution. Thus, an immunogenetic difference could hypothetically reflect two autoimmune diseases, triggered by different factors, directed against different antigens and requiring different prevention and treatment.

In conclusion, the immunogenetic heterogeneity repeatedly observed between R/R MS and PCP MS, together with clinical, epidemiological and radiological differences, supports the separation of these two groups as separate disease entities, a measure that could be of value in epidemiologic, pathogenetic and therapeutic studies of MS.

The expert technical assistance of Dr Chunmao Leng is greatly appreciated. This study was supported by grants from the Swedish Medical Research Council (project numbers 0870 an 00793), the Swedish Association of the Neurologically Disabled, the Sigurd and Elsa Golje Memorial Foundation, the Swedish Society of Medicine and the Söderbergs Foundations.

1 Todd JA, Bell JI, McDevitt HO. HLA-DQ ${ }_{\beta}$ gene contributes to susceptibility and resistance to insulin-dependent diabetes mellitus. Nature 1987;329:599-604.

2 Gregersen PK, Silver J, Winchester RJ. The shared epitope hypothesis. An approach to understanding the molecular genetics of susceptibility to rheumatoid arthritis. Arthritis Rheum 1987;30:1205-13.

3 Olerup O, Smith CIE, Hammarström L. Different amino acids at position 57 of the HLA-DQ $\beta$ chain associated with susceptibility and resistance to IgA deficiency.

4 Marcadet A, Massart C, Semana G, et al. Association of class II HLA-DQ $\beta$ chain DNA restriction fragments with multiple sclerosis. Immunogenetics 1985;22:93-6.

5 Olerup O, Hillert J, Fredrikson S, et al. Primarily chronic progressive and relapsing/remitting multiple sclerosis: Two immunogenetically distinct disease entities. Proc Nat Acad Sci USA 1989;86:7113-7.

6 Vartdal F, Sollid LM, Vandvik B, Markussen G, Thorsby E. Patients with multiple sclerosis carry DQB1 genes which encode shared polymorphic amino acid sequences. Hum Immunol 1989;25:103-10.

7 Spurkland A, Skjold Rønningen K, Vandvik B, Thorsby E, Vartdal F. HLA-DQA1 and HLA-DQB1 genes may
jointly determine susceptibility to develop multiple sclejointly determine susceptibility to de

8 Ødum N, Hyldig-Nielsen JJ, Morling N, et al. HLA-DP antigens are involved in the susceptibility to multiple sclerosis. Tissue Antigens 1988;31:235-7.

9 Olerup O, Hillert J. HLA class II associated genetic susceptibility in multiple sclerosis: A critical evaluation Tissue Antigens 1991;38:1-15.

10 Larsen JP, Kvaale G, Riise T, Nyland H, Aarli J. Multiple sclerosis-more than one disease? Acta Neurol Scand 1985;72:145-50.

11 Thompson A, Kermode A, MacManus D, et al. Pathogenesis of progressive multiple sclerosis. Lancet 1989;i: 1322-3.

12 Thompson A, Kermode A, Wicks D, et al. Major differences in the dynamics of primary and secondary progressive multiple sclerosis. Ann Neurol 1991;29:53-62.

13 Bidwell JL, Bidwell EA, Laundy GJ, Klouda PT, Bradley BA. Allogenotypes defined by short $\mathrm{DQ} \alpha$ and $\mathrm{DQ} \beta$ cDNA probes correlate with, and define splits of HLADQ serological specificities. Mol Immunol 1987;24: 513-22.

14 Carlsson B, Wallin J, Böhme J, Möller E. HLA-DR-DQ haplotypes defined by restriction fragment length analysis: Correlation to serology. Hum Immunol 1987;20: 95-113.

15 Hyldig-Nielsen JJ, Morling N, Odum N, et al. Restriction fragment length polymorphism of the HLA-DP subregion and correlations to HLA-DP phenotypes. Proc Natl Acad Sci 1987;84:1644-8.

16 Hyldig-Nielsen JJ, Odum N, Morling N, Sveigaard A Restriction fragment: length polymorphism (RFLP) of a "new" HLA-DP specificity, CDP-HEI. Tissue Antigen 1988;31:161-3.

17 Lanchbury JSS, Hall MA, Welsh KI, Panayi GS. Sequence analysis of the HLA-DR4B1 subtypes: Additional first domain variability is detected by oligonucleotide hybridization and nucleotide sequencing. Hum Immunol 1990; 27:136-44.

18 Zetterqvist $\mathrm{H}$, Olerup O. Abstract. XVIth Congress of the Scandinavian Transplantation Society, Reykjavik, Iceland 1991.

19 Cullen CG, Middleton D, Savage DA, Hawkins S. HLA$D R$ and - DQ DNA genotyping in multiple sclerosis patients in Northern Ireland. Hum Immunol 1991;30: $1-6$.

20 Goodkin D, Hertsgaard D, Rudick R. Exacerbation rates and adherence to disease type in a prospectively followedup population with multiple sclerosis. Arch Neurol 1989;46:1107-12.

21 Gudmundson KR. Clinical studies of multiple sclerosis in Iceland. Acta Neurol Scand 1971;47 (suppl 48):1-78.

22 Leibowitz U, Alter M. Clinical factors associated with increased disability in multiple sclerosis. Acta Neurol increased disability in
Scand $1970 ; 46: 53-70$.

23 Confavreux C, Aimard G, Devic M. Course and prognosis of multiple sclerosis assessed by the computerized data processing of 349 patients. Brain 1980;103:281-300.

24 van Lambalgen RV, Sanders EACM, D'Amaro J. Sex distribution, age of onset and HLA profiles in two types of multiple sclerosis: A role for sex hormones and microbial infections in the development of autoimmunity. $₹$ Neurol Sci 1986;76:13-21.

25 Minderhoud JH, van der Hoeven JH, Prange AJA. Course and prognosis of chronic progressive multiple sclerosis. Acta Neurol Scand 1988;78:10-5.

26 Schädlich H-J, Karbe H, Felgenhauer K. The prevalence of locally-synthesized virus antibodies in various forms of locally-synthesized virus antibodies in various
multiple sclerosis. $\mathcal{f}$ Neurol Sci 1987;80:343-9.

27 Noseworthy J, Paty D, Wonnacott T, Feasby T, Ebers G. Multiple sclerosis after age 50. Neurology 1983;33: Multiple

28 Madigand M, Oger JJ-F, Fauchet R, Sabouraud O, Genetet B. HLA profiles in multiple sclerosis suggest two forms of disease and the existence of protective haplotypes. $\mathcal{F}$ Neurol Sci 1982;53:519-29.

29 Sinha AA, Bell RB, Steinman L, McDevitt HQ. Oligonucleotide dot-blot analysis of HLA-DQ $\beta$ alleles associated with multiple sclerosis. F Neuroimmunol 1991;32:61-5.

30 Marsh SGE, Bodmer JG. HLA class II nucleotide sequences, 1991. Immunogenetics 1991;33:321-34. 